\title{
Trial of a laminated material to reduce glare in cataract
}

\author{
D. W. HILL, J. SILVER, AND L. H. LIGHT \\ From Moorfields Eye Hospital, London, and the Clinical Research Centre, Medical Research Council, London
}

SUMMARY A recently-introduced laminated material which accepts light only over a small angle on either side of the normal was compared to standard Polaroid sunglasses. A preliminary trial failed to show any superiority of the new material in reducing glare for patients with moderate cataract.

During the development of cataract patients experience considerable disturbance of vision before the disability warrants operation. The use of tinted glasses to reduce dazzle has been recommended (Duke-Elder, 1969). Recently the introduction of a laminated material, transmitting light only within a small angle of acceptance on either side of the normal to the surface of the material, has made it possible to try an alternative method for reducing dazzle. A pilot study has been conducted to assess its possible value in clinical practice.

\section{Patients and methods}

Ten patients, all women, with senile cataract of varying morphology were invited to take part in the study; all complained of reduced vision. The refraction of each patient's eyes was tested, and each was given spectacles with optimum correction and 2 pairs of clip-on lenses, one a standard Polaroid sunglass, the other containing the laminated material. The patents were asked to compare the value of spectacles alone and each of the two clip-on glasses in various types of lighting, outdoors and indoors, for distance and for reading. After a fortnight their reactions were assessed independently by the surgeon, who did not know which clip-on glass contained which material.

\section{Results}

Table 1 shows the ages, corrected visual acuities, and cataract morphology of the patients. Only 3 of the 10 patients, numbers $1,8,10$, found any appreciable advantage from the clip-on glass, and

Address for reprints: Professor D. W. Hill, Moorfields Eye Hospital, High Holborn, London WCIV 7AN
Table 1 Details of patients studied

\begin{tabular}{|c|c|c|c|c|c|c|}
\hline & Age & $\begin{array}{l}\text { Corrected } \\
V A \text { right } \\
\text { and left }\end{array}$ & $\begin{array}{l}\text { Binocular } \\
\text { Polaroid }\end{array}$ & $\begin{array}{l}V A \text { with } \\
\text { Laminated }\end{array}$ & $\begin{array}{l}\text { Type of } \\
\text { cataract }\end{array}$ & $\begin{array}{l}\text { Preferred } \dagger \\
\text { material }\end{array}$ \\
\hline 1 & 63 & $6 / 18: 6 / 18$ & $6 / 24$ & $6 / 18$ & $\mathbf{N}$ & Polaroid \\
\hline 2 & 69 & $6 / 9: 6 / 18$ & $6 / 9$ & $6 / 9$ & $\mathbf{W}$ & - \\
\hline 3 & 72 & $6 / 12: 6 / 12$ & $6 / 12$ & $6 / 12$ & C & (Polaroid) \\
\hline 4 & 88 & $6 / 18: 6 / 12$ & $6 / 18$ & $6 / 18$ & $\mathbf{w}$ & (Laminated) \\
\hline 5 & 70 & $6 / 18: 6 / 18$ & $6 / 12$ & $6 / 18$ & $\mathbf{W}$ & (Polaroid) \\
\hline 6 & 71 & $6 / 12: 6 / 18$ & $6 / 18$ & $6 / 24$ & $\mathrm{~N}, \mathrm{~W}, \mathrm{C}$ & (Polaroid) \\
\hline 7 & 79 & $6 / 36: 6 / 24$ & $6 / 24$ & $6 / 36$ & W (N) & - \\
\hline 8 & 68 & $6 / 18: 6 / 12$ & $6 / 36$ & $6 / 36$ & $\mathbf{w}$ & Polaroid \\
\hline 9 & $70 *$ & $6 / 18: 6 / 18$ & $6 / 18$ & $6 / 18$ & $\mathbf{w}$ & - \\
\hline 10 & 74 & $6 / 12: 6 / 24$ & $6 / 36$ & $6 / 36$ & $\mathbf{N}$ & Polaroid \\
\hline
\end{tabular}

VA $=$ visual acuity. $\mathbf{N}=$ nuclear. $\mathbf{W}=$ cuneiform. $\mathbf{C}=$ cupuliform. -Limited trial indoors. +Entries in brackets where patients preferred plain correction.

in all cases the material preferred was the Polaroid. A further 4 patients, though preferring a plain spectacle correction, were able to differentiate one clip-on glass as more advantageous; 3 were in favour of Polaroid and 1 of the laminated material. Corrected visual acuity with the clip-on glass was often lower than with a plain correction.

\section{Discussion}

The majority of patients in this pilot study had cuneiform cataract, which, it was anticipated, would be most likely to produce dazzle when subjected to strong light. Only 1 of the 3 reporting favourably on the Polaroid clip-on glass had cuneiform cataract. The 
other 2 had nuclear cataract and may have benefited from the slightly enlarged pupil resulting from reduced illumination.

Admittedly this study was carried out during the autumn, s: when high levels of outdoor illumination are not usual, but it seems that the dazzle factor is less important than anticipated; and the use of a laminated material with directionally sensitive transmission was not particularly helpful in promoting the vision of patients with moderate cataract.

\section{Reference}

Duke-Elder, S. (1969). System of Ophthalmology, Vol. 11, p. 246. Kimpton: London. 